\title{
First chemo-enzymatic synthesis of the $(R)$-Taniguchi lactone and substrate profiles of CAMO and OTEMO, two new Baeyer- Villiger monooxygenases
}

\author{
Florian Rudroff $^{1}$ (D) Michael J. Fink ${ }^{1,2} \cdot$ Ramana Pydi $^{1} \cdot$ Uwe T. Bornscheuer $^{3}$ (D) Marko D. Mihovilovic $^{1}$
}

Received: 4 October 2016/Accepted: 6 November 2016/Published online: 21 December 2016

(c) The Author(s) 2016. This article is published with open access at Springerlink.com

\begin{abstract}
Abstract This study investigates the substrate profile of cycloalkanone monooxygenase and 2-oxo- $\Delta^{3}-4,5,5-$ trimethylcyclopentenylacetyl-coenzyme A monooxygenase, two recently discovered enzymes of the BaeyerVilliger monooxygenase family, used as whole-cell biocatalysts. Biooxidations of a diverse set of ketones were performed on analytical scale: desymmetrization of substituted prochiral cyclobutanones and cyclohexanones, regiodivergent oxidation of terpenones and bicyclic ketones, as well as kinetic resolution of racemic cycloketones. We demonstrated the applicability of the title enzymes in the enantioselective synthesis of $(R)-(-)$ Taniguchi lactone, a building block for the preparation of various natural product analogs such as ent-quinine.
\end{abstract}

Florian Rudroff

florian.rudroff@tuwien.ac.at

1 Institute of Applied Synthetic Chemistry, TU Wien, Getreidemarkt 9/163-OC, 1060 Vienna, Austria

2 Present Address: Department of Chemistry and Chemical Biology, Harvard University, 12 Oxford St, Cambridge, MA 02138, USA

3 Department of Biotechnology and Enzyme Catalysis, Institute of Biochemistry, University of Greifswald, 17487 Greifswald, Germany

\section{Graphical abstract}

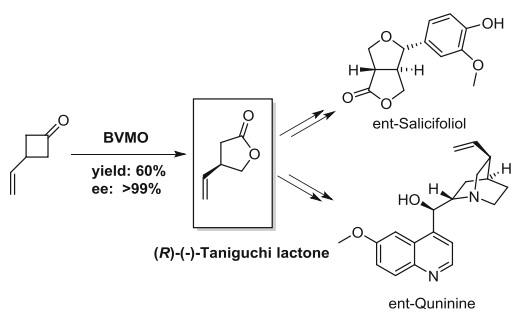

Keywords Biotransformation .

Baeyer-Villiger oxidation · Taniguchi lactone

\section{Introduction}

Baeyer-Villiger monooxygenases are well-known enzymes, promoting the oxidation of cyclic and linear ketones into the corresponding lactones or esters by activating molecular oxygen in water at ambient temperature. This enzyme family catalyzes the biological equivalent to the chemical Baeyer-Villiger oxidation, discovered by Adolf Bayer and Victor Villiger in 1899 [1], which requires peracids and rather harsh reaction conditions. Major drawbacks of the classic stoichiometric synthetic route are the poor tolerance of other functional groups (e.g., towards double bonds and heteroatoms), the need of potentially explosive reagents (e.g., meta-chloroperbenzoic acid), and the reduced possibility of chiral induction [2-10].

The resulting esters and, especially if obtained optically enriched, chiral lactones are promising building blocks for the synthesis of valuable intermediates of drugs and natural products [11]. During the last decades, applicability of BVMOs has been demonstrated in multiple accounts: 
desymmetrization of prochiral substrates, kinetic resolutions of racemic ketones, and regioselective transformations [12-19]. We had previously profiled the substrate scope of a range of BVMOs [20-24], allowing us to correlate their stereopreference with protein sequence [25]. This led to a significant clustering of BVMOs into subgroups, and eventually to the development of a decision guidance tool [24], enabling a pre-selection of best-performing biocatalysts for a particular substrate class.

Camphor monooxygenase (CAMO) from the ascomycete Cylindrocarpon radicicola ATCC 11011 was recently reported as the first recombinant BVMO originating from a eukaryotic organism [26]; it possesses a general activity for both cyclic and linear ketones. In contrast, recombinant 2-oxo- $\Delta^{3}-4,5,5$-trimethylcyclopentenylacetyl-coenzyme A monooxygenase (OTEMO) from Pseudomonas putida NCIMB 10007 showed activity for cyclic ketones, preferentially $[27,28]$. Whenever new BVMOs are discovered, it is of particular interest to know their activity, catalytic performance, and selectivity in relation to previously characterized enzymes. The distinct positions of CAMO and OTEMO in the phylogenetic tree (Fig. 1) of BVMOs motivated our efforts of in-depth substrate profiling of these new biocatalysts.

Furthermore, we wished to demonstrate the applicability of both title enzymes by developing a new biocatalytic approach for the synthesis of optically pure $(R)-(-)$-Taniguchi lactone. The enantiomeric $(S)-(+)$ lactone [29] has been used as a building block for the synthesis of various natural products, e.g., salicifoliol, threosyl-5'-deoxyphosphonic acid, and purine analogs [30], including the first stereoselective synthesis of quinine [31]. Several attempts succeeded to obtain the Taniguchi lactone in optically pure form via chiral resolution by chiral agents [32-34]. Synthetic accessibility of the $(R)-(-)$-Taniguchi lactone will provide a novel approach for the synthesis of, e.g., ent-quinine and entsalicifoliol, respectively.

Here, we present a comprehensive substrate profile of two novel BVMOs (CAMO, OTEMO) and the first chemoenzymatic synthesis of the $(R)-(-)$-Taniguchi lactone in enantiopure form via a desymmetrization step.
Fig. 1 Phylogenetic tree of BVMOs. The sequences of the investigated enzymes CAMO and OTEMO are highlighted. CAMO belongs to the $\mathrm{CHMO}_{\text {Acineto }}$ subgroup, whereas OTEMO clustered separately from known groups of correlated sequence and stereopreference

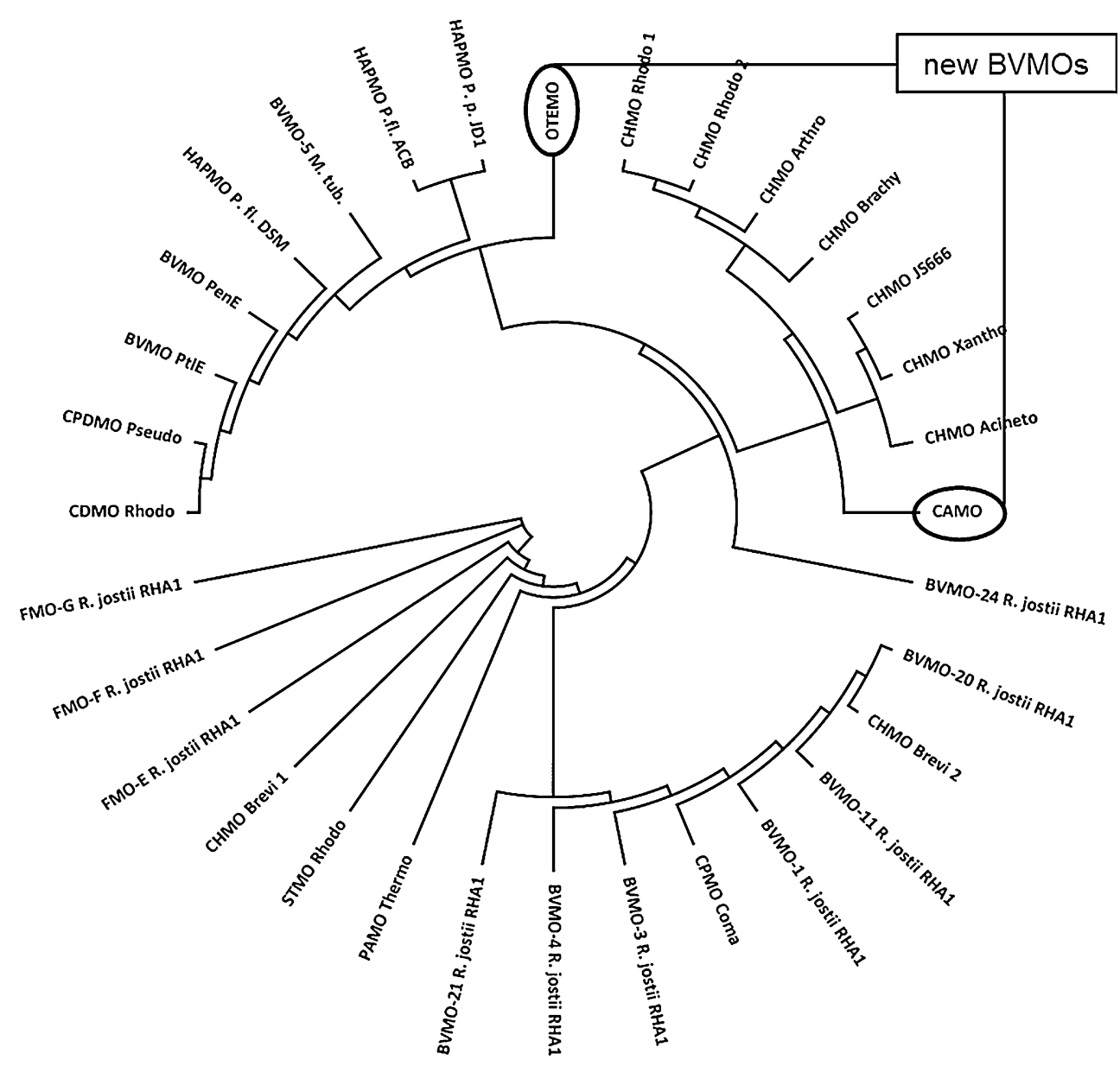




\section{Results and discussion}

We investigated the sequence homology of CAMO and OTEMO. Their divergent positioning in the phylogenetic analysis (CAMO clustered with CHMO-type enzymes, whereas OTEMO branched off at an early point; Fig. 1) suggested a distinctly different substrate profile between the biocatalysts. To determine the catalyst performance a diverse array of substrates (e.g., 2- and 4-substituted cyclohexanones, 3 -substituted cyclobutanones, and terpenones) was investigated. The experiments were conducted on analytical scale and the results obtained were compared and referenced to published values. The substrates were grouped into kinetic resolutions, regiodivergent oxidations, and desymmetrization reactions.

\section{Kinetic resolutions}

We tested a set of $\alpha$-substituted cyclohexanones, starting from small methyl 1a, to allyl $\mathbf{2 a}$, and more bulky substituents,

\section{Scheme 1}

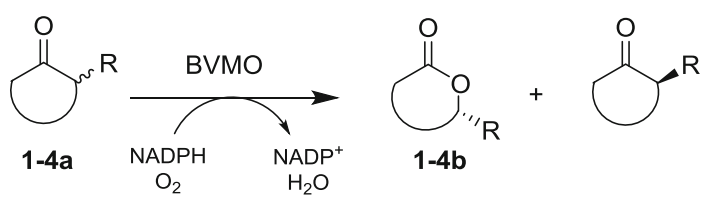

including phenyl 3a and benzyl 4a residues (Scheme 1). The enantiomeric ratio $E$ was estimated using Sih's equation.

$$
E=[\ln (1-\mathrm{eeS})-\ln (1+\mathrm{eeS} / \mathrm{eeP})] /
$$

$[\ln (1+$ eeS $)-\ln (1+$ eeS/eeP $)]$,

from ee of substrate (eeS) and ee of product (eeP) values, and compared to already published reference biotransformations (Table 1). Since CAMO is closely related in sequence to $\mathrm{CHMO-type} \mathrm{enzymes,} \mathrm{we} \mathrm{expec-}$ ted its stereopreference to align with the cluster; the hypothesis was found to be true with all tested compounds of the class. Also, OTEMO had the same sense of chiral induction. Nevertheless, except for the transformation of 2-phenylcyclohexanone with CAMO $(E>200)$, the title enzymes were only poorly selective ( $E=3-69$ ), when compared to the best reference results using CDMO or CHMOs.

\section{Regiodivergent biotransformations}

The second set of substrates was composed of fused bicyclic cyclobutanones and monocyclic terpenones to test the regioselectivity of CAMO and OTEMO. For these particular substrate classes the formation of two regioisomers is often observed: the "normal" lactone $(n)$, based on the nucleophilicity-driven rearrangement, and the "abnormal" lactone ( $a b n)$ governed by stereoelectronic effects (Scheme 2) [36].

Table 1 Kinetic resolutions of 2-substituted cyclohexanones

\begin{tabular}{|c|c|c|c|c|c|c|c|c|}
\hline \multirow[t]{2}{*}{ Substrate } & \multirow[t]{2}{*}{$R$} & \multirow[t]{2}{*}{ Comp. no } & \multicolumn{3}{|l|}{ CAMO } & \multicolumn{3}{|l|}{ OTEMO } \\
\hline & & & $\operatorname{Conv}(\%)^{\mathrm{a}}$ & $\%$ ee $\mathrm{S} / \%$ ee $\mathrm{P}$ & $E^{b}$ & Conv $(\%)^{\mathrm{a}}$ & $\%$ ee $\mathrm{S} / \%$ ee $\mathrm{P}$ & $E^{\mathrm{b}}$ \\
\hline & $\mathrm{Me}$ & 1 & 56 & $86(-) / 60(+)$ & 11 & 33 & $23(-) / 40(+)$ & 3 \\
\hline & Allyl & 2 & 46 & $53(-) / 88(-)$ & 28 & 60 & $43(-) / 50(-)$ & 5 \\
\hline$R$ & $\mathrm{Ph}$ & 3 & 48 & $96(-) / 99(+)$ & $>200$ & 32 & $43(-) / 95(+)$ & 64 \\
\hline & $\mathrm{Bn}$ & 4 & 54 & $62(-) / 91(-)$ & 41 & 58 & $73(-) / 94(-)$ & 69 \\
\hline
\end{tabular}

\begin{tabular}{|c|c|c|c|c|c|c|c|}
\hline \multirow[t]{2}{*}{ Substrate } & \multirow[t]{2}{*}{$R$} & \multirow[t]{2}{*}{ Comp. no } & \multicolumn{5}{|c|}{ Reference biotransformation } \\
\hline & & & $\operatorname{Conv}(\%)^{\mathrm{a}}$ & $\%$ ee $\mathrm{S} / \%$ ee $\mathrm{P}$ & $E^{b}$ & Biocatalyst & References \\
\hline & $\mathrm{Me}$ & 1 & 58 & $99(+) / 92(-)$ & 125 & CDMO & [24] \\
\hline 0 & Allyl & 2 & 50 & $99(-) / 99(-)$ & $>200$ & $\mathrm{CHMO}_{\text {Acineto }}$ & [35] \\
\hline & $\mathrm{Ph}$ & 3 & 48 & $76(-) / 99(+)$ & $>200$ & $\mathrm{CHMO}_{\text {Xantho }}$ & [36] \\
\hline & $\mathrm{Bn}$ & 4 & 47 & $91(-) / 99(-)$ & $>200$ & $\mathrm{CDMO}$ & [24] \\
\hline
\end{tabular}

\footnotetext{
${ }^{a}$ Relative conversion (Conv) of starting material and enantiomeric excess values determined by chiral phase GC; sign of optical rotation is given in parentheses and assigned on the basis of reference biotransformations; $e_{S}$ (substrate), $e_{\mathrm{P}}$ (product)

b Enantiomeric ratio $E$ was estimated using Sih's equation
} 
Scheme 2

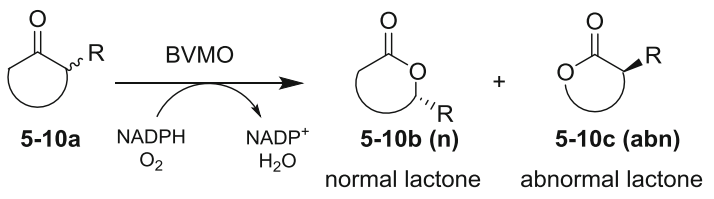

In general, fused bicyclic cyclobutanones are good substrates for BVMO-mediated biooxidations due to the highly favored alleviation of ring strain by insertion of an oxygen atom (Table 2). Ketone 5a was fully converted by CAMO and gave an equal ratio of $n$ and $a b n$ lactones $\mathbf{5 b} / \mathbf{c}$. Enantioselectivity for the $n$ lactone was good [ee $88 \%(-)$ ] and excellent for the $a b n$ lactone [ee 99\% (-)]. Again, CAMO gave comparable results to previously published data of CHMO-type BVMOs. In contrast, OTEMO gave $\mathbf{5 b} / \mathbf{c}$ in a $70 / 30$ ratio of $n / a b n$ with moderate stereoselectivity for the $n$ lactone [ee $46 \%(-)$ ] and excellent optical purity for the $a b n$ lactone [ee $99 \%(-)$ ]. Contrasting results were obtained for ketone 6a: whereas CAMO gave a 70/30 $n / a b n$ ratio with poor [6b: ee $41 \%(+)]$ to excellent [6c: ee 98\% (+)] enantioselectivities, OTEMO transformations yielded in a $1 / 1$ ratio of $a b n / n$ lactone with perfect optical purity for both regioisomers. This result is the best obtained so far for this compound (6a). The last example of this substrate class (7a) was fully converted by both enzymes, with slight preference towards the $a b n$ lactone 7c. Optical purities were moderate to poor for the $n$ lactone $\mathbf{7 b}$ and high for the $a b n$ lactone 7c for both enzymes.
A second tier of substrates for regiodivergent reactions consisted of optically pure terpenones $(\mathbf{8}-\mathbf{1 0 a})$. Previous studies revealed that CHMO family enzymes preferably gave $n$ lactones, whereas CPMO-type enzymes formed $a b n$ lactones [10]. With those compounds, the preference of migration strongly depends on the absolute configuration of the starting material. We tested three different terpenones 8-10a with CAMO and OTEMO (Table 3). The former showed poor regioselectivity; in contrast OTEMO was highly selective in the oxidation of substrates $9 \mathbf{a}$ and 10a, yielding the $\mathrm{n}$ lactones $\mathbf{9}, \mathbf{1 0 b}$ exclusively. These results demonstrated that neither CAMO nor OTEMO behaved like a classical CHMO- or CPMO-type BVMO.

\section{Desymmetrization reactions}

A series of 11 prochiral ketones was biooxidized by CAMO and OTEMO in desymmetrization reactions (Scheme 3; Table 4). All 3-substituted cyclobutanones 1115a were fully converted to the lactones 11-15b. 3-Vinylcyclobutanone 11a was transformed with perfect stereoselectivity by both tested BVMOs (both giving (-)11b with $99 \%$ ee).

CAMO's stereopreference for cyclobutanones 12-14a was divergent from other CHMO-type BVMOs; it produces the enantiomers usually obtained by CPMO-type transformations, but with much higher selectivity (Table 4). Lactones $\mathbf{1 2 b}$ and $\mathbf{1 4 b}$ were thus obtained with $97 \%(+)$ and $95 \%(+)$ ee. The optical purity of lactones 13b, 15b was much higher than previously published

Table 2 Regiodivergent Baeyer-Villiger oxidations of fused and racemic (cis) bicyclic cyclobutanones

\begin{tabular}{|c|c|c|c|c|c|c|c|c|c|}
\hline \multirow[t]{2}{*}{ Substrate } & \multirow[t]{2}{*}{ Comp. no } & \multicolumn{2}{|l|}{ CAMO } & \multicolumn{2}{|l|}{ OTEMO } & \multicolumn{4}{|c|}{ Reference biotransformation } \\
\hline & & $\begin{array}{l}\% \text { Conv }^{\mathrm{a}} / \\
\text { ratio }^{\mathrm{b}}\end{array}$ & $\begin{array}{l}\% \mathrm{ee}^{\mathrm{c}} \\
n / a b n\end{array}$ & $\begin{array}{l}\% \text { Conv }^{\mathrm{a}} / \\
\text { ratio }^{\mathrm{b}}\end{array}$ & $\begin{array}{l}\% \mathrm{ee}^{\mathrm{c}} \\
n / a b n\end{array}$ & $\begin{array}{l}\% \text { Conv }^{\mathrm{a}} / \\
\text { ratio }^{\mathrm{b}}\end{array}$ & $\begin{array}{l}\% \mathrm{ee}^{\mathrm{c}} \\
n / a b n\end{array}$ & Biocatalyst & References \\
\hline & 5 & +++ & $88(-) / 99(-)$ & +++ & $46(-) / 99(-)$ & +++ & rac. $/ 99(+)$ & СРMO & [37] \\
\hline & & $53: 47$ & & & & $\begin{array}{c}97: 03 \\
+++ \\
51: 49\end{array}$ & $95(-) / 99(-)$ & $\mathrm{CHMO}_{\text {Acineto }}$ & [25] \\
\hline & 6 & $\begin{array}{l}+++ \\
70: 30\end{array}$ & $41(+) / 98(+)$ & $\begin{array}{l}+++ \\
50: 50\end{array}$ & $97(+) / 99(+)$ & $\begin{array}{l}+++ \\
87: 13\end{array}$ & $14(+) / 99(+)$ & $\mathrm{CPMO}_{\mathrm{Coma}}$ & [37] \\
\hline & & & & & & $\begin{array}{l}+++ \\
70: 30\end{array}$ & $44(+) / 99(+)$ & $\mathrm{CHMO}_{\text {Acineto }}$ & {$[37]$} \\
\hline & 7 & $\begin{array}{l}+++ \\
68: 32\end{array}$ & $46(+) / 99(+)$ & $\begin{array}{l}+++ \\
89: 11\end{array}$ & $20(+) / 95(+)$ & $\begin{array}{l}+++ \\
75: 25\end{array}$ & $33(-) / 56(-)$ & $\mathrm{CPMO}_{\text {Coma }}$ & [37] \\
\hline & & & & & & $\begin{array}{l}+++ \\
97: 3\end{array}$ & $12(+) / 88(+)$ & $\mathrm{CHMO}_{\text {Acineto }}$ & [37] \\
\hline
\end{tabular}

rac. racemic

${ }^{\mathrm{a}}$ Relative conversion (Conv) of starting material determined by chiral phase GC after $24 \mathrm{~h}:+++>90 \%,++50-90 \%,+<50 \%$

b Ratio of regioisomers (normal:abnormal)

c Enantiomeric excess values determined by chiral phase GC; sign of optical rotation is given in parenthesis and assigned on the basis of reference biotransformations 
Table 3 Regiodivergent transformations of optically pure terpenones

\begin{tabular}{|c|c|c|c|c|c|c|}
\hline \multirow[t]{2}{*}{ Substrate } & \multirow[t]{2}{*}{ Comp. no } & \multirow{2}{*}{$\begin{array}{l}\mathrm{CAMO}^{\mathrm{c}} \\
\% \text { Conv }^{\mathrm{a}} / \\
\text { ratio }^{\mathrm{b}}\end{array}$} & \multirow{2}{*}{$\begin{array}{l}\text { OTEMO }^{\mathrm{c}} \\
\% \text { Conv }^{\mathrm{a}} / \\
\text { ratio }^{\mathrm{b}}\end{array}$} & \multicolumn{3}{|c|}{ Reference biotransformation $^{c}$} \\
\hline & & & & $\begin{array}{l}\% \text { Conv }^{\mathrm{a}} / \\
\text { ratio }^{\mathrm{b}}\end{array}$ & Biocatalyst & References \\
\hline \multirow{4}{*}{$(+)$} & \multirow[t]{4}{*}{8} & +++ & +++ & +++ & \multirow[t]{2}{*}{$\mathrm{CHMO}_{\text {Acineto }}$} & \multirow[t]{2}{*}[22]{} \\
\hline & & $53: 47$ & $11: 89$ & $0: 100$ & & \\
\hline & & & & ++ & \multirow[t]{2}{*}{$\mathrm{CHMO}_{\text {Brevi } 1}$} & \multirow[t]{2}{*}[22]{} \\
\hline & & & & $51 / 49$ & & \\
\hline & \multirow[t]{4}{*}{9} & \multirow{4}{*}{$\begin{array}{l}+++ \\
70: 30\end{array}$} & \multirow{4}{*}{$\begin{array}{l}+++ \\
100: 0\end{array}$} & +++ & \multirow[t]{2}{*}{$\mathrm{CHMO}_{\text {Acineto }}$} & \multirow[t]{2}{*}[22]{} \\
\hline & & & & 100:0 & & \\
\hline & & & & +++ & \multirow[t]{2}{*}{$\mathrm{CPMO}_{\mathrm{Coma}}$} & \multirow[t]{2}{*}{ [22] } \\
\hline & & & & $0: 100$ & & \\
\hline & \multirow[t]{2}{*}{10} & +++ & +++ & +++ & \multirow[t]{2}{*}{$\mathrm{CHMO}_{\text {Acineto }}$} & \multirow[t]{2}{*}[22]{} \\
\hline & & $68: 32$ & 100:0 & 100:0 & & \\
\hline$(+)$ & & & & & & \\
\hline
\end{tabular}

${ }^{a}$ Relative conversion (Conv) of starting material determined by chiral phase GC after $24 \mathrm{~h}:+++>90 \%,++50-90 \%,+<50 \%$

b Ratio of regioisomers (normal:abnormal)

c Enantiomeric excess $>99 \%$

Scheme 3

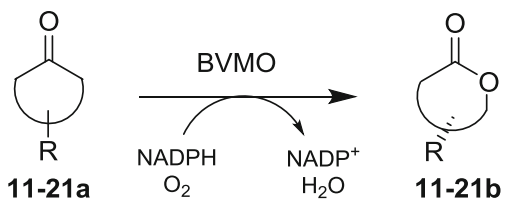

values $[\mathbf{1 3 b}=94 \%(-)$ vs $63 \%(-)$ and $\mathbf{1 5 b}=92 \%(+)$ vs $73 \%(+)]$. These lactones are important intermediates for the synthesis of tricyclic benzomorphan analogs, (+)harzialactone $\mathrm{A}$, chiral tricyclic amines [38-40], and for the synthesis of lignans such as enterolactone, hinokinin, arctigenin [41], the synthesis of optically pure gosmin A and schizandrin [42]. In all cases, OTEMO had the same stereopreference as CAMO, but was less stereoselective.

Both enzymes fully converted all tested 4-substituted cyclohexanones (substrates 16-21a). Remarkably, lactone 17b was formed with perfect enantiomeric purity [ee 99\%, $(+)$ ] using CAMO, thus surpassing the best known result. Both optical antipodes of lactone $\mathbf{1 8 b}$ could be obtained by CAMO and OTEMO, respectively: whereas CAMO gave the levorotatory isomer with $77 \%$ ee, OTEMO yielded in the antipodal product with $98 \%$ ee. A similar trend was observed for substrate 19a, where CAMO produced (-)19b with $95 \%$ ee, and OTEMO gave $(+)-\mathbf{1 9 b}$ with $96 \%$ ee.
The latter result again exceeded the best previously obtained value with wild-type BVMOs.

Substrates 20a and 21a were transformed with very good enantioselectivity by both enzymes, as commonly found with other BVMOs.

\section{Chemo-enzymatic synthesis of $(R)-(-)$-Taniguchi lactone}

After identification of CAMO and OTEMO as excellent catalysts for the enantioselective synthesis of lactone $\mathbf{1 1 b}$, we investigated a new chemo-enzymatic route to Taniguchi lactone $\mathbf{1 1 b}$, starting from readily available 1,3-butadiene. This lactone is a valuable chiral building block for the synthesis of several natural products (Scheme 4).

We performed a $[2+2]$ cycloaddition using dichloroketone, generated in situ from trichloroacetyl chloride in the presence of activated zinc [46]. Subsequent reduction of the dichloroketone led to 3-Vinylcyclobutanone 11a in $44 \%$ over two steps. We then screened a library of cycloketone-converting BVMOs, composed of 13 wild-type enzymes, plus mutants of $\mathrm{CHMO}_{\text {Acineto }}$ and $\mathrm{CPMO}_{\mathrm{Coma}}$, that had been generated in previous studies [47, 48].

Most wild-type BVMOs gave the desired Taniguchi lactone with excellent conversion and optical purity (ee $>95 \%$ ), exclusively with $(R)$-configuration (data not shown). All mutants of $\mathrm{CHMO}_{\text {Acineto }}$ that where designed 
Table 4 Desymmetrizations of substituted prochiral cycloketones 11-21a

\begin{tabular}{|c|c|c|c|c|c|c|c|c|c|c|}
\hline \multirow[t]{2}{*}{ Structure } & \multirow[t]{2}{*}{$R$} & \multirow[t]{2}{*}{ Comp. no } & \multicolumn{2}{|l|}{ CAMO } & \multicolumn{2}{|l|}{ OTEMO } & \multicolumn{4}{|c|}{ Reference biotransformation } \\
\hline & & & $\operatorname{Conv}(\%)^{\mathrm{a}}$ & ee $(\%)^{\mathrm{b}}$ & $\operatorname{Conv}(\%)^{\mathrm{a}}$ & ee $(\%)^{\mathrm{b}}$ & $\operatorname{Conv}(\%)^{\mathrm{a}}$ & ee $(\%)^{b}$ & Biocatalyst & References \\
\hline & 3-Vinyl & 11 & 100 & $99(-)$ & 100 & $99(-)$ & n.a. & n.a. & n.a. & This work \\
\hline & $\mathrm{Bn}$ & 12 & 99 & $97(+)$ & 98 & $11(-)$ & +++ & $44(+)$ & HAPMO & {$[43]$} \\
\hline & & & & & & & +++ & $93(-)$ & $\mathrm{CHMO}_{\text {Brevi1 }}$ & \\
\hline & 3-(3-MeOBn) & 13 & 100 & $94(-)$ & 100 & $82(-)$ & +++ & $63(-)$ & $\mathrm{CPMO}_{\text {Coma }}$ & [43] \\
\hline & 3-(4-MeOBn) & 14 & 95 & $95(+)$ & 100 & $64(+)$ & +++ & $24(+)$ & $\mathrm{CPMO}_{\mathrm{Coma}}$ & [43] \\
\hline & 3-(3,4,5-tri-MeOBn) & 15 & 100 & $92(+)$ & 87 & $63(+)$ & +++ & $79(+)$ & $\mathrm{CHMO}_{\text {Brevi1 }}$ & [43] \\
\hline & $\mathrm{Me}$ & 16 & 100 & $99(-)$ & 100 & $58(+)$ & +++ & $99(-)$ & CDMO & [24] \\
\hline & & & & & & & +++ & $64(+)$ & $\mathrm{CPMO}_{\text {Coma }}$ & [44] \\
\hline & $\mathrm{OH}$ & 17 & 100 & $>99(+)$ & n.a. & n.a. & +++ & $99(-)$ & $\mathrm{CHMO}_{\text {Xantho }}$ & {$[24]$} \\
\hline & & & & & & & +++ & $44(+)$ & $\mathrm{CHMO}_{\text {Brevi2 }}$ & \\
\hline & $t \mathrm{Bu}$ & 18 & 98 & $77(-)$ & 100 & $98(+)$ & +++ & $99(-)$ & CPDMO & [18] \\
\hline $\mathrm{R}$ & COOEt & 19 & 99 & $95(-)$ & 57 & $96(+)$ & +++ & $99(-)$ & CPDMO & [18] \\
\hline & & & & & & & +++ & $64(+)$ & $\mathrm{CPMO}_{\mathrm{Coma}}$ & [18] \\
\hline 0 & $\mathrm{H}, \mathrm{H}$ & 20 & 100 & $97(-)$ & 100 & $96(-)$ & +++ & $99(-)$ & CDMO & [24] \\
\hline & $\mathrm{H}, \mathrm{OH}$ (trans) & 21 & 100 & $96(+)$ & 100 & $94(+)$ & +++ & $96(+)$ & $\mathrm{CHMO}_{\text {Acineto }}$ & {$[45]$} \\
\hline
\end{tabular}

n.a. not applicable

${ }^{\text {a }}$ Relative conversion (Conv) of starting material determined by chiral phase GC after $24 \mathrm{~h}:+++>90 \%,++50-90 \%,+<50 \%$

${ }^{b}$ Enantiomeric excess values determined by chiral phase GC; sign of optical rotation is given in parenthesis and assigned on the basis of reference biotransformations

Scheme 4

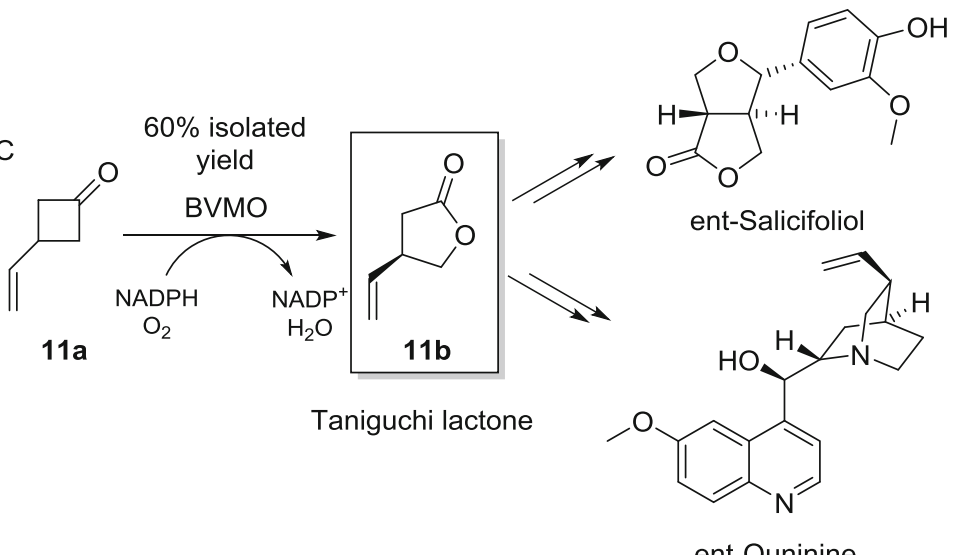

for enantiodivergence towards cyclobutanones and cyclohexanones, showed a reduced stereospecificity, and no inversion of the selectivity was observed with any biocatalyst. A similar trend was seen using the variants of $\mathrm{CPMO}_{\mathrm{Coma}}$. We then performed biotransformation on a preparative scale $(50 \mathrm{mg})$ with CAMO (57\% isolated yield) and OTEMO (60\% isolated yield) to confirm the results obtained in the screening reactions on the analytical scale. Overall, we were able to synthesize enantiomerically pure Taniguchi lactone $\mathbf{1 1 b}$ in $26 \%$ yield over three steps having ee $99 \%(-)$ optical purity by biocatalytic desymmetrization. 


\section{Conclusion}

In this work, we reported the substrate scope and compared the performance of CAMO and OTEMO as whole-cell biocatalysts overexpressed in E. coli. We investigated commercially available and in-house synthesized racemic 2-substituted cyclohexanones, fused bicyclic cyclobutanones, optically pure terpenones, prochiral cyclobutanones and cyclohexanones, all either serving as model substrates or intermediates in the synthesis of natural compounds. The biocatalysts gave remarkable results in the desymmetrization of cyclobutanones and -hexanones, in some cases improving the enantioselectivity significantly over prior best values. The other reaction classes were generally not converted with a performance equal to reference BVMOs.

A biocatalytic route for the synthesis of optically pure $(R)-(-)$-Taniguchi lactone was established, starting from 1,3-butadiene via biooxidation of 3-Vinylcyclobutanone with CAMO and OTEMO as recombinant whole-cell catalysts. This synthesis is an interesting alternative approach to known preparations of the target lactone.

\section{Experimental}

All purchased reagents were used without further purification. All solvents were distilled prior to use. Substrates and reference compounds for substrate acceptance screening were synthesized according to literature-known protocols. Silica gel 60 was used for column chromatography and progress of the reactions was monitored by thin layer chromatography (TLC). The analysis and identification of all molecules were conducted using chiral phase GC (BGB 173 and BGB 175 Column: $30 \mathrm{~m} \times 0.25 \mathrm{~mm}$ ID, $0.25 \mu \mathrm{m}$ film). NMR spectra were recorded on a Bruker AC $200(200 \mathrm{MHz})$ spectrometer. Specific rotation was determined using an Anton Paar Polarimeter MCP500. LB medium was not buffered and used without $\mathrm{pH}$ correction; ampicillin and kanamycin concentrations were set to $100 \mathrm{mg} / \mathrm{cm}^{3}$ (LB $\mathrm{Lamp}_{\text {and }}$ and $\left.\mathrm{LB}_{\text {kan }}\right)$. Cloning, expression and characterization of CAMO [26] and OTEMO [27, 28] is described elsewhere.

\section{Substrate acceptance screening reactions}

A baffled Erlenmeyer flask was charged with $3 \mathrm{~cm}^{3} \mathrm{LB}_{\mathrm{amp}}$ medium, inoculated with a bacterial single colony from an agar plate, and incubated at $37{ }^{\circ} \mathrm{C}$ and $200 \mathrm{rpm}$ in an orbital shaker overnight. $\mathrm{LB}_{\text {amp }}$ medium $\left(10 \mathrm{~cm}^{3}\right)$ was inoculated with $1 \%(\mathrm{v} / \mathrm{v})$ of the overnight culture and incubated for $1-2 \mathrm{~h}$ under the same conditions until an optical density of $0.2-0.6$ was reached. Then, $2 \mathrm{~cm}^{3}$ of fermentation medium was charged to 12 -well plates and IPTG $(0.2 \mathrm{mM})$ was added. Substrates were added as $0.8 \mathrm{M}$ solutions in 1,4-dioxane to a final concentration of $4 \mathrm{mM}$. The plates were sealed with adhesive film and incubated at $24{ }^{\circ} \mathrm{C}$ and $200 \mathrm{rpm}$ in an orbital shaker for up to $24 \mathrm{~h}$. Analytical samples were prepared by extraction of $0.5 \mathrm{~cm}^{3}$ of fermentation mixture with $1.0 \mathrm{~cm}^{3}$ of EtOAc (supplemented with $1 \mathrm{mM}$ methyl benzoate as internal standard) after centrifugation to separate the biomass.

\section{3-Vinylcyclobutanone (11a)}

1,3-Butadiene $\left(1 \mathrm{~g}, 18.5 \mathrm{mmol}, 49 \mathrm{~cm}^{3}\right.$ of a $15 \mathrm{wt} \%$ solution of 1,3-butadiene in hexane) was added to freshly prepared and dry $\mathrm{Cu} / \mathrm{Zn}$ couple [49] $(3.5 \mathrm{~g}, 52 \mathrm{mmol})$ at $0{ }^{\circ} \mathrm{C}$ under Ar atmosphere. A mixture of $9.5 \mathrm{~g}$ trichloroacetyl chloride $(52 \mathrm{mmol})$ and $7.8 \mathrm{~g} \mathrm{POCl}_{3}(50 \mathrm{mmol})$ was added dropwise at $0{ }^{\circ} \mathrm{C}$ under argon within $2-4 \mathrm{~h}$. The mixture was stirred overnight at r.t., zinc salts were removed by filtration through a pad of Celite; the filtrate was diluted with $150 \mathrm{~cm}^{3}$ of diethyl ether and carefully diluted with $100 \mathrm{~cm}^{3}$ of cold water. The organic phase was separated and washed with aq. $\mathrm{NaHCO}_{3}\left(4 \times 50 \mathrm{~cm}^{3}\right)$, then with $100 \mathrm{~cm}^{3}$ brine and dried over anhydrous $\mathrm{Na}_{2} \mathrm{SO}_{4}$. The solvent was removed in vacuo and the residue was used in the next step without further purification.

The crude residue $(2.1 \mathrm{~g})$ was dissolved in $10 \mathrm{~cm}^{3}$ acetic acid and added dropwise to a suspension of zinc in $30 \mathrm{~cm}^{3}$ acetic acid within $1 \mathrm{~h}$, followed by heating to $70-80{ }^{\circ} \mathrm{C}$ for another hour. The reaction mixture was cooled to r.t., filtered through a pad of Celite, diluted with $100 \mathrm{~cm}^{3}$ water, and extracted with dichloromethane $\left(4 \times 50 \mathrm{~cm}^{3}\right)$. The combined organic phases were washed with saturated aq. $\mathrm{NaHCO}_{3}\left(4 \times 50 \mathrm{~cm}^{3}\right)$, then with $100 \mathrm{~cm}^{3}$ brine, dried over anhydrous $\mathrm{Na}_{2} \mathrm{SO}_{4}$, and the solvent was removed in vacuo to obtain the desired product 11a as a yellow oil. Yield: $44 \%$ (782 mg) over two steps; ${ }^{1} \mathrm{H}$ NMR $(200 \mathrm{MHz}$, $\left.\mathrm{CDCl}_{3}\right): \delta=6.02(\mathrm{ddd}, 1 \mathrm{H}), 5.01-5.36(\mathrm{~m}, 2 \mathrm{H}), 3.39(\mathrm{~s}$, $1 \mathrm{H}), 2.89-3.36(\mathrm{~m}, 4 \mathrm{H}) \mathrm{ppm} ;{ }^{13} \mathrm{C} \mathrm{NMR}\left(50 \mathrm{MHz}, \mathrm{CDCl}_{3}\right)$ : $\delta=206.7,140.2,114.6,52.6,26.9 \mathrm{ppm}$.

rac-4-Vinyldihydrofuran-2(3H)-one (Taniguchi lactone) (11b)

2-Buten-1,4-diol (6 g, $68 \mathrm{mmol}), 22 \mathrm{~g}$ triethyl orthoacetate (136 mmol), and $2.25 \mathrm{~g} p$-hydroquinone $(20.4 \mathrm{mmol})$ were stirred at $120{ }^{\circ} \mathrm{C}$. Generated ethanol was removed using a Dean-Stark apparatus. After the condensation of ethanol had ceased, the temperature was increased to $150{ }^{\circ} \mathrm{C}$ for $24 \mathrm{~h}$. The crude residue was isolated via distillation under reduced pressure $\left(60-70{ }^{\circ} \mathrm{C}, 36 \mathrm{mbar}\right)$ and the product was obtained by column chromatography $\mathrm{rac}-\mathbf{1 1 b}$ as a yellow oil to serve as reference material for chiral analytics. Yield: $42 \%$ (3.35 g); ${ }^{1} \mathrm{H}$ NMR (200 MHz, $\left.\mathrm{CDCl}_{3}\right): \delta=5.76(\mathrm{~m}$, 
1H), 5.07-5.27 (m, 2H), $4.42(\mathrm{~m}, 1 \mathrm{H}), 4.00(\mathrm{~m}, 1 \mathrm{H}), 3.21$ $(\mathrm{m}, 1 \mathrm{H}), 2.65(\mathrm{~m}, 1 \mathrm{H}), 2.36(\mathrm{~m}, 1 \mathrm{H}) \mathrm{ppm} ;{ }^{13} \mathrm{C} \mathrm{NMR}$ $\left(50 \mathrm{MHz}, \mathrm{CDCl}_{3}\right): \delta=176.5,135.7,117.4,72.1,39.7$, $34.1 \mathrm{ppm}$.

\section{(R)-4-Vinyldihydrofuran-2(3H)-one (Taniguchi lactone) (11b)}

An overnight culture with $\mathrm{LB}_{\text {kan }}$ medium $\left(3 \mathrm{~cm}^{3}\right)$, inoculated with a bacterial single colony from an agar plate and incubated at $37{ }^{\circ} \mathrm{C}$ and $200 \mathrm{rpm}$ in an orbital shaker was prepared. A baffled Erlenmeyer $\left(500 \mathrm{~cm}^{3}\right)$ flask was charged with $100 \mathrm{~cm}^{3}$ of $\mathrm{LB}_{\text {kan }}$ medium and inoculated with $1 \%(\mathrm{v} / \mathrm{v})$ of the overnight culture and incubated for 1-2 $\mathrm{h}$ under the same conditions until an optical density of $0.2-0.6$ was reached. IPTG $(0.2 \mathrm{mM})$ and $50 \mathrm{mg}$ ketone 11a $\left(0.52 \mathrm{mmol}\right.$, dissolved in $200 \mathrm{~mm}^{3}$ of 1 ,4-dioxane) was added. The reaction flask was incubated at $24{ }^{\circ} \mathrm{C}$ and $200 \mathrm{rpm}$ in an orbital shaker until full conversion was determined via GC analysis (18-24 h). After completion of the reaction, the reaction mixture was centrifuged $(12000 \mathrm{x}$ $\left.\mathrm{g}, 15 \mathrm{~min}, 4^{\circ} \mathrm{C}\right)$. The supernatant was extracted with EtOAc $\left(5 \times 40 \mathrm{~cm}^{3}\right)$, and the pooled organic phases were dried over anhydrous $\mathrm{Na}_{2} \mathrm{SO}_{4}$, and concentrated. The product was purified by column chromatography using light petroleum and EtOAc. Yields: $57 \%(33 \mathrm{mg})$ for CAMO and 60\% (35 mg) for OTEMO. ${ }^{1} \mathrm{H}$ NMR and ${ }^{13} \mathrm{C}$ NMR were identical to the racemic Taniguchi lactone [32]. $[\alpha]_{\mathrm{D}}^{25}=-7.0\left(c=1\right.$ in $\left.\mathrm{CHCl}_{3}\right), 99 \%$ ee.

Acknowledgements Open access funding provided by Austrian Science Fund (FWF). This work was funded by the Austrian Scientific Foundation FWF (Grant No. I-723-N17). M. J. F. was funded within the EU-FP7 program Oxygreen (Grant \#212281).

Open Access This article is distributed under the terms of the Creative Commons Attribution 4.0 International License (http:// creativecommons.org/licenses/by/4.0/), which permits unrestricted use, distribution, and reproduction in any medium, provided you give appropriate credit to the original author(s) and the source, provide a link to the Creative Commons license, and indicate if changes were made.

\section{References}

1. Baeyer A, Villiger V (1899) Chem Berichte $33: 124$

2. Leisch H, Morley K, Lau PC (2011) Chem Rev 111:4165

3. Mihovilovic MD, Rudroff F, Groetzl B (2004) Curr Org Chem 8:1057

4. Ito K (2012) In: Asymmetric Baeyer-Villiger oxidation. Elsevier B.V., Amsterdam, p 1

5. Michelin RA, Sgarbossa P, Scarso A, Strukul G (2010) Coord Chem Rev 254:646

6. Sugiishi T, Matsugi M, Hamamoto H, Amii H (2015) RSC Adv 5:17269

7. Uyanik M, Ishihara K (2013) ACS Catal 3:513

8. Xu S, Wang Z, Zhang X, Zhang X, Ding K (2008) Angew Chem Int Ed 47:2840
9. Watanabe A, Uchida T, Ito K, Katsuki T (2002) Tetrahedron Lett 43:4481

10. Bolm C, Luong TKK, Schlingloff G (1997) Synlett 1151

11. Mihovilovic MD (2006) Curr Org Chem 10:1265

12. Kamerbeek NM, Janssen DB, van Berkel WJH, Fraaije MW (2003) Adv Synth Catal 345:667

13. Bucko M, Gemeiner P, Schenkmayerova A, Krajcovic T, Rudroff F, Mihovilovic MD (2016) Appl Microbiol Biotechnol 100:6585

14. Muschiol J, Peters C, Oberleitner N, Mihovilovic MD, Bornscheuer UT, Rudroff F (2015) Chem Commun 51:5798

15. Rudroff F, Fink MJ, Mihovilovic MD (2016) Miscellaneous key non- $\mathrm{C}-\mathrm{C}$ bond forming enzyme reactions. In: Goswami A, Stewart JD (eds) Organic synthesis using biocatalysis. Academic Press, USA, p 243

16. Leipold F, Rudroff F, Mihovilovic MD, Bornscheuer UT (2013) Tetrahedron Asymmetry 24:1620

17. Fink MJ, Fischer TC, Rudroff F, Dudek H, Fraaije MW, Mihovilovic MD (2011) J Mol Catal B Enzym 73:9

18. Fink MJ, Rudroff F, Mihovilovic MD (2011) Bioorg Med Chem Lett 21:6135

19. Oberleitner N, Peters C, Muschiol J, Kadow M, Sass S, Bayer T, Schaaf P, Iqbal N, Rudroff F, Mihovilovic MD, Bornscheuer UT (2013) ChemCatChem 5:3524

20. Mihovilovic MD, Müller B, Schulze A, Stanetty P, Kayser MM (2003) Eur J Org Chem 2243

21. Mihovilovic MD, Rudroff F, Müller B, Stanetty P (2003) Bioorg Med Chem Lett 13:1479

22. Cernuchova P, Mihovilovic MD (2007) Org Biomol Chem $5: 1715$

23. Fink MJ, Fischer TC, Rudroff F, Dudek H, Fraaije MW, Mihovilovic MD (2011) J Mol Catal B Enzym 73:9

24. Fink MJ, Rial DV, Kapitanova P, Lengar A, Rehdorf J, Cheng Q, Rudroff F, Mihovilovic MD (2012) Adv Synth Catal 354:3491

25. Mihovilovic MD, Rudroff F, Grötzl B, Kapitan P, Snajdrova R, Rydz J, Mach R (2005) Angew Chem Int Ed 44:3609

26. Leipold F, Wardenga R, Bornscheuer UT (2012) Appl Microbiol Biotechnol 94:705

27. Kadow M, Loschinski K, Sass S, Schmidt M, Bornscheuer UT (2012) Appl Microbiol Biotechnol 96:419

28. Leisch H, Shi R, Grosse S, Morley K, Bergeron H, Cygler M, Iwaki H, Hasegawa Y, Lau PC (2012) Appl Environ Microbiol 78:2200

29. Kondo K, Mori F (1974) Chem Lett 3:741

30. Lian Jin Liu EK, Hong Joon Hee (2012) Nucleosides Nucleotides Nucleic Acids 31:411

31. Stork G, Niu D, Fujimoto A, Koft ER, Balkovec JM, Tata JR, Dake GR (2001) J Am Chem Soc 123:3239

32. von Kieseritzky F, Wang Y, Axelson M (2014) Org Process Res Dev 18:643

33. Ishibashi F, Taniguchi E (1998) Phytochem 49:613

34. Ishibashi F, Taniguchi E (1988) Bull Chem Soc Jpn 61:4361

35. Rial DV, Cernuchova P, van Beilen JB, Mihovilovic MD (2008) J Mol Catal B Enzym 50:61

36. Noyori R, Sato T, Kobayashi H (1983) Bull Chem Soc Jpn $56: 2661$

37. Mihovilovic MD, Kapitan P, Kapitanova P (2008) ChemSusChem 1:143

38. Kotkar SP, Suryavanshi GS, Sudalai A (2007) Tetrahedron Asymmetry 18:1795

39. Ketterer C, Wünsch B (2012) Eur J Org Chem 2012:2428

40. Ketterer C, Grimme S, Weckert E, Wünsch B (2006) Tetrahedron Asymmetry 17:3046

41. Bode JW, Doyle MP, Protopopova MN, Zhou Q-L (1996) J Org Chem 61:9146

42. Tanaka M, Mukaiyama C, Mitsuhashi H, Wakamatsu T (1992) Tetrahedron Lett 33:4165 
43. Rudroff F, Rydz J, Ogink FH, Fink M, Mihovilovic MD (2007) Adv Synth Catal 349:1436

44. Wang S, Kayser MM, Iwaki H, Lau PCK (2003) J Mol Catal B Enzym 22:211

45. Mihovilovic MD, Rudroff F, Grötzl B, Stanetty P (2005) Eur J Org Chem 809

46. Dehmlow EV, Kinnius J, Buchholz M, Hannemann D (2000) J Prakt Chem Chem-Ztg 342:409
47. Mihovilovic MD, Rudroff F, Winninger A, Schneider T, Schulz F, Reetz MT (2006) Org Lett 8:1221

48. Clouthier CM, Kayser MM, Reetz MT (2006) J Org Chem 71:8431

49. Rudroff F, Rydz J, Ogink FH, Fink M, Mihovilovic MD (2007) Adv Synth Catal 349:1436 